\title{
A Conexão Afetiva nas Intervenções Desenvolvimentistas para Crianças Autistas
}

Affective Connection In Developmental Interventions For Autistic Children

La Conexión Afectiva En Las Intervenciones Desarrollistas Para Niños Autistas

Olívia FioreCorreia \& Carolina Lampreia

Pontifícia Universidade Católica do Rio de Janeiro
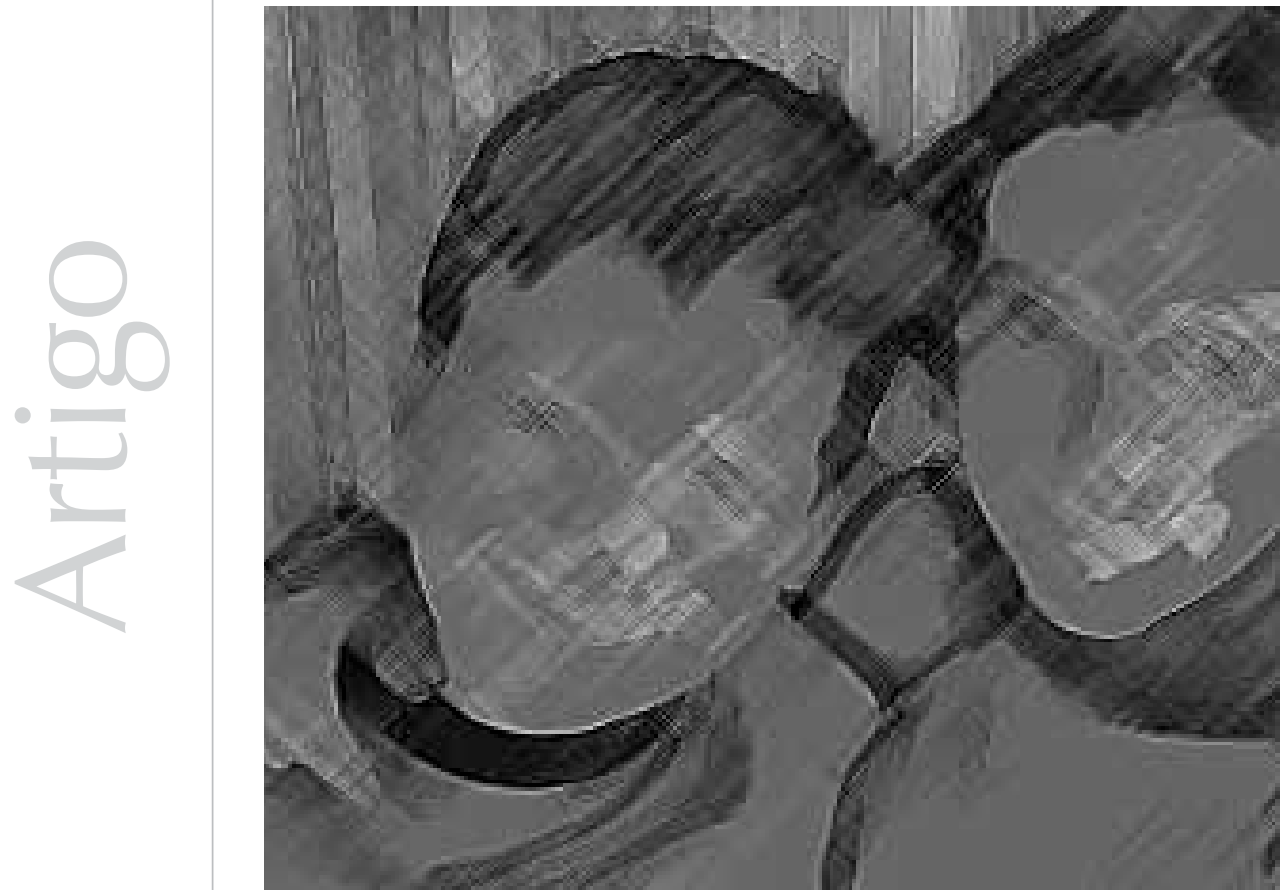
Resumo: O presente trabalho explica como a conexão afetiva é fundamental para o desenvolvimento infantil típico e como é utilizada nas intervenções para crianças autistas ou com risco autístico. Utilizando a abordagem desenvolvimentista, que procura compreender o desenvolvimento da criança autista à luz do desenvolvimento da criança típica, o objetivo do artigo é salientar a importância da conexão afetiva nas intervenções desenvolvimentistas. Realizamos uma revisão da literatura desenvolvimentista, considerando como a capacidade de conexão afetiva do bebê humano contribui para o desenvolvimento infantil e como falhas nessa área do desenvolvimento de crianças autistas ocasionam prejuízos significativos para elas. Assim, pudemos rever os programas de intervenção SCERTS e DIR, de modo a compreendermos como consideram a conexão afetiva. Conclui-se que os programas, embora busquem o desenvolvimento global das crianças autistas, apresentam limitações em relação ao entendimento da conexão afetiva como a precursora do desenvolvimento infantil (SCERTS) e à busca de estratégias objetivas para que ela possa ser desenvolvida nessas crianças (DIR). Entretanto, observações relacionadas às pesquisas e à literatura desenvolvimentista sugerem que tais limitações podem ser superadas, desde que se ressalte o papel fundamental da conexão afetiva para a diminuição do desvio do desenvolvimento das crianças autistas.

Palavras-chave: Conexão afetiva. Abordagem desenvolvimentista. Intervenção precoce. Transtorno autista.

Abstract: This study explains how affective connection is crucial to typical child development and is used in autistic children interventions. Using a developmental approach, which seeks to understand the development of autistic children compared to the typical child development, the article aims at highlighting the importance of affective connection in developmental interventions. We reviewed the developmental literature, considering how human infant's ability of affective connection contributes to child development. This failure in the development of autistic children produces important impairments. Thus, we review the programs SCERTS and DIR in order to understand how they consider affective connection. The conclusion is that these programs, although seeking the overall development of autistic children, have limitations: in relation to the understanding of affective connection as a precursor of child's development (SCERTS) and in the search of objective strategies to develop it on these children (DIR). However, observations about research and developmental literature suggest that such limitations can be overcomed provided that the role of affective connection to decrease the deviation of autistic children development is stressed.

Keywords: Affective connection. Developmental approach. Early intervention. Autistic disorder.

Resumen: El presente trabajo explica como la conexión afectiva es fundamental para el desarrollo infantil típico y como es utilizada en las intervenciones para niños autistas o con riesgo autístico. Utilizando el abordaje desarrollista, que busca comprender el desarrollo del niño autista a la luz del desarrollo del niño típico, el objetivo del artículo es destacar la importancia de la conexión afectiva en las intervenciones desarrollistas. Realizamos una revisión de la literatura desarrollista, considerando como la capacidad de conexión afectiva del bebé humano contribuye para el desarrollo infantil y como fallos en esa área del desarrollo de niños autistas ocasionan perjuicios significativos para ellos. Así, pudimos rever los programas de intervención SCERTS y DIR, de modo de comprender como consideran la conexión afectiva. Se concluye que los programas, aunque busquen el desarrollo global de los niños autistas, presentan limitaciones con relación al entendimiento de la conexión afectiva como la precursora del desarrollo infantil (SCERTS) y a la búsqueda de estrategias objetivas para que esta pueda ser desarrollada en esos niños (DIR). No obstante, observaciones relacionadas a las investigaciones y a la literatura desarrollista sugieren que tales limitaciones pueden ser superadas, desde que se resalte el papel fundamental de la conexión afectiva para la disminución del desvío del desarrollo de los niños autistas.

Palabras clave: Conexión afectiva. Abordaje desarrollista. Intervención precoz. Trastorno autista.

O transtorno autista é um transtorno que acomete o desenvolvimento global de crianças em seus três primeiros anos de vida, e cujas principais dificuldades se encontram nas interações sociais, na comunicação e no comportamento dessas crianças (DSM-IV-TR, 2002). Devido ao crescimento da identificação precoce dos primeiros sinais do transtorno antes dos dois primeiros anos de vida (Braido,
2006; Lampreia \& Lima, 2008; Osterling \& Dawson, 1994), intervenções precoces de base desenvolvimentista visam a reverter ou a amenizar essas dificuldades iniciais, de modo que não ocasionem outras dificuldades para o desenvolvimento dessas crianças.

Em países como Estados Unidos e Inglaterra, a abordagem desenvolvimentista tem sido 
Para Hobson (2002),

um dos principais defensores da abordagem desenvolvimentista, esses prejuízos primários se encontram nas falhas inatas na capacidade de conexão afetiva das crianças autistas. o alicerce para as principais intervenções precoces utilizadas em crianças autistas na atualidade (Greenspan \& Wieder, 2006; Prizant, Wetherby, Rubin, \& Laurent, 2003). Em nossa sociedade, embora essa abordagem ainda seja pouco conhecida, alguns estudos a têm utilizado para a compreensão e o tratamento do transtorno autista (Braido, 2006; Caminha, 2008; Campos, 2007; Fiore-Correia, 2005, 2010; Fiore-Correia, Lampreia, \& Sollerode-Campos, 2008; Lampreia, 2004, 2007; Lampreia \& Lima, 2008; Oliveira, 2009).

Essa abordagem sustenta que o transtorno autista é mais bem compreendido quando o desenvolvimento das crianças autistas é comparado à trajetória do desenvolvimento infantil típico, a fim de se identificar o que ocorre de distinto no desenvolvimento das primeiras. Nesse caso, acredita-se que o desenvolvimento das crianças autistas sofra um desvio em relação às crianças típicas, devido a prejuízos primários inatos que acabam ocasionando prejuízos secundários decorrentes.

Para Hobson (2002), um dos principais defensores da abordagem desenvolvimentista, esses prejuízos primários se encontram nas falhas inatas na capacidade de conexão afetiva das crianças autistas. Segundo o autor, a conexão afetiva é definida pela capacidade inata de expressividade, responsividade e sensibilidade do recém-nascido ao afeto do outro. No desenvolvimento infantil típico, a conexão afetiva é o que permite ao recém-nascido ser movido afetivamente pelos seus cuidadores e responder a esse afeto. Logo, através dela, recém-nascido e cuidadores vivenciam e respondem às interações a partir de suas experiências afetivas. Isso possibilita ao recémnascido o envolvimento em intensas interações sociais que dão condições para o fomento dos comportamentos do desenvolvimento infantil típico. Por sua vez, o desenvolvimento desses comportamentos desencadeia novas expressões e o compartilhamento de afetos que geram novas interações e, por conseguinte, o desenvolvimento de novos comportamentos, em um ciclo interminável para o desenvolvimento humano.

No caso do desenvolvimento da criança autista, segundo Hobson, com as falhas precoces na capacidade de conexão afetiva de crianças que posteriormente recebem o diagnóstico de transtorno autista, elas não conseguem ser sensíveis e responsivas aos afetos das pessoas, ao mesmo tempo em que não conseguem ser expressivas em relação ao próprio afeto. Isso prejudica a sua capacidade de responder às interações a partir das expressões afetivas ocorridas entre os parceiros de interações, ocasionando déficits severos em seu relacionamento social. Tais déficits acarretam, por conseguinte, prejuízos secundários identificados pelos déficits na capacidade de brincar, na fala e nos comportamentos das crianças autistas (DSMIV-TR, 2002).

Seguindo esse pensamento, as intervenções precoces de base desenvolvimentista, que procuram intervir nas dificuldades iniciais do transtorno, deveriam ter como principais estratégias o desenvolvimento da conexão afetiva das crianças autistas ou com risco autístico, ou seja, que apresentam os primeiros sinais do transtorno, mas que não alcançaram a idade adequada para o diagnóstico. No entanto, ao contrário do esperado, a maioria das intervenções precoces que segue essa abordagem atua sobre os prejuízos decorrentes das falhas da conexão afetiva dessas crianças (Klinger \& Dawson, 1992; Prizant et al., 2003). Apenas um programa que segue essa abordagem o faz, embora não explicite objetivamente o modo como o realiza (Greenspan \& Wieder, 2006).

Considerando esse fato, o objetivo do presente trabalho é ressaltar a importância da conexão afetiva para o desenvolvimento das crianças autistas e como ela precisa ser considerada a principal estratégia das intervenções precoces 
de base desenvolvimentista que atuam com crianças autistas ou com risco autístico.

Para alcançarmos tal intento, precisamos, em primeiro lugar, reconhecer o papel da conexão afetiva para o desenvolvimento infantil típico, ao mesmo tempo em que precisamos identificar as consequências de suas falhas para o desenvolvimento das crianças autistas. Posteriormente, em um segundo momento, podemos revisar dois principais programas de intervenção precoce de base desenvolvimentista e identificar o papel que a conexão afetiva ocupa nas suas estratégias de intervenção; somente assim poderemos identificar se tais programas salientam o impacto da conexão afetiva para o desenvolvimento das crianças autistas, restando às considerações finais um esforço para alçar a conexão afetiva ao verdadeiro patamar que ela deve ocupar, ou seja, o de estratégia principal das intervenções precoces que atendem crianças autistas ou que estão em risco de obter o diagnóstico posteriormente.

Todo esse processo se torna imprescindível, visto que conhecer e avaliar criticamente as intervenções precoces mais utilizadas atualmente no atendimento às crianças autistas é fundamental para a busca de um tratamento mais eficaz para elas. Afinal, oferecer um tratamento mais adequado para essas crianças pode permitir-lhes amenizar e até mesmo sanar os seus prejuízos, dando-lhes a chance de tentar retomar a trajetória do desenvolvimento infantil típico. E essa deve ser a preocupação de todos os envolvidos no cuidado e no atendimento a essas crianças.

\section{A conexão afetiva no desenvolvimento infantil típico e no desenvolvimento da criança autista}

Encontramos em muitos autores desenvolvimentistas (Greenspan \& Wieder, 2000, 2006; Hobson, 1990, 1993a, 1993b,
1998, 2002, 2005a, 2005b, 2005c, 2007, 2009; Stern, 1974, 1992), a afirmação de que as interações afetivas entre recém-nascidos e seus cuidadores é o que possibilita o seu desenvolvimento cognitivo, simbólico, subjetivo e emocional. Embora Hobson (2002) seja o autor que definiu conceitualmente a capacidade de conexão afetiva, os autores acima citados mostram, em suas respectivas obras, o papel do afeto no desenvolvimento infantil. Por esse motivo, utilizaremos o conceito de conexão afetiva de Hobson, associado às contribuições dos outros autores, para compreender o desenvolvimento tanto das crianças típicas quanto das autistas.

Considerando o desenvolvimento infantil típico, nos nove primeiros meses de vida, a conexão afetiva é identificada nas interações diádicas entre o bebê e os seus cuidadores, o que Trevarthen e Aitkhen (2001) denominam intersubjetividade primária. Nessa fase, a conexão afetiva dá condições a algumas interações e comportamentos imprescindíveis para o desenvolvimento do bebê, como o desenvolvimento do self emergente e nuclear do bebê, o desenvolvimento das interações contingentes e de alternância de turno e o comportamento antecipatório, o contato ocular, o sorriso responsivo e as vocalizações (Stern, 1992).

Em relação ao desenvolvimento do self emergente, nos dois primeiros meses de vida do bebê, as interações diádicas com o seu cuidador se vinculam às suas necessidades fisiológicas, como o sono, a fome e o frio e, portanto, se relacionam às suas experiências sensoriais. Tais experiências sensoriais estão sempre associadas às experiências afetivas do bebê. Para Greenspan e Benderly (1999), isso equivale a dizer que há um código dual, ou seja, uma relação direta, entre a experiência sentida e o afeto ligado a essa experiência, que possibilita ao recém-nascido vivenciar o modo como as expressões afetivas são sentidas através, por exemplo, de um toque sobre a sua pele 
ou o modo como falam com ele. Essa relação faz com que o bebê não apenas seja sensível às expressões afetivas de seus cuidadores mas também ao modo como essas expressões são sentidas, capacitando-o a unificar tais experiências sensoriais em qualidades globais de suas vivências. Para Stern, isso, juntamente à nossa capacidade inata de percepção amodal, caracterizada pela nossa capacidade de transferir uma experiência perceptual sentida em uma modalidade, como o tato, para outra, como a visão, dá-nos condição de desenvolver o nosso self emergente, o que seria, em síntese, a capacidade do bebê de vivenciar uma experiência integradora oriunda das trocas afetivas ocorridas através de suas primeiras experiências sensoriais. Tal capacidade é fundamental para o desenvolvimento humano, visto que é o primeiro passo para o desenvolvimento do self.

Todavia, a partir desse desenvolvimento, as interações deixam de envolver apenas as necessidades fisiológicas do bebê para contemplar o envolvimento social dos parceiros de interação. Nesse caso, a conexão afetiva passa a ser expressa em maior gama de trocas sociais, possibilitando, então, o desenvolvimento de novas interações e comportamentos. É por esse motivo que Stern afirma que, após os dois meses de idade, os bebês se tornam extremamente sociais. Segundo Brazelton e Cramer (1990) e Klinger e Dawson (1992), isso é possível devido ao desenvolvimento de interações sociais que capacitam ainda mais o envolvimento afetivo entre os bebês e os seus cuidadores. Brazelton e Cramer enfatizam o aparecimento das interações contingentes, caracterizadas pelas interações em que o bebê responde contingentemente às ações de seus cuidadores e vice-versa, enquanto Klinger e Dawson destacam o surgimento das interações de alternância de turno e comportamento antecipatório, definidas pela capacidade do bebê de antecipar a ação do outro por saber como ele irá se comportar. Em ambos os casos, é necessário que o bebê esteja tão envolvido afetivamente na interação com o adulto a ponto de ser capaz de vivenciar um sentido de causalidade em suas interações e antecipar-se ao comportamento das pessoas, o que permitirá desenvolver o início de sua intencionalidade; para Bates (1979), essa seria a capacidade de a criança utilizar determinado meio para atingir um fim. E, embora nessa fase o bebê ainda não seja capaz disso, ele começa a perceber que as suas ações geram efeitos nos comportamentos das outras pessoas.

Para Stern (1974), essas interações propiciam o desenvolvimento de dois comportamentos fundamentais para o desenvolvimento do bebê: a capacidade de sorriso responsivo do bebê e o início de suas vocalizações. Para o autor, junto ao comportamento de contato ocular, tais comportamentos são imprescindíveis para o desenvolvimento humano porque intensificam o contato afetivo da díade e as trocas afetivas entre os parceiros de interações, além de fazer com que ambos regulem os seus próprios comportamentos e expressões afetivas através da busca e da recusa de seu parceiro de interação para a troca social.

Nessa idade, Stern (1992) enfatiza também o desenvolvimento do self nuclear do bebê, fundamental para o desenvolvimento humano, visto que ele proporciona experiências organizadoras para o corpo físico do bebê. Sendo assim, a partir do desenvolvimento do self emergente e do desenvolvimento dessas novas interações sociais, o bebê experiencia uma organização nuclear, através de quatro vivências: a vivência de autocoerência, quando ele experiencia que as suas ações e afetos surgem de um corpo físico integrado; as vivências integradoras de autoagência, quando experiencia a autoria de suas próprias ações ao vivenciar as repercussões que elas trazem ao ambiente; a vivência da autoafetividade, à medida que vivencia a integração dos próprios afetos, e a vivência da auto-história, considerando que todas essas experiências apresentam um senso de duração e continuidade. 
Até o momento, então, a conexão afetiva deu condição para o ganho de interações e de comportamentos do desenvolvimento infantil através das interações diádicas. Por sua vez, tais interações e comportamentos possibilitam que o bebê, a partir de nove meses de idade, se envolva em interações triádicas, desenvolvendo a sua intersubjetividade secundária (Trevarthen \& Aitkhen, 2001). As interações triádicas são aquelas interações em que o bebê compartilha a sua atenção por um objeto ou evento de seu interesse com o seu parceiro de interação e vice-versa. Tal habilidade se relaciona ao desenvolvimento do self subjetivo do bebê e dos comportamentos comunicativos não verbais da atenção compartilhada. Tais comportamentos são os precursores do aparecimento da referenciação social, teoria da mente, jogos simbólicos, fala, aquisição de regras sociais e auto-consciência.

Segundo Stern, as interações triádicas se tornam possíveis porque, a partir do momento em que o bebê vivencia o seu self nuclear e identifica os selves nucleares de seus parceiros de interação, passa a perceber que diferentes selves apresentam focos de atenção distintos, mas que podem ser compartilhados através de um interesse em comum por algo do ambiente. Mas, devido à conexão afetiva, Hobson (2005c) enfatiza que os bebês e os parceiros de interação não compartilham apenas o seu foco de atenção, mas também, e principalmente, os seus estados afetivos, o que, segundo Stern, nesse momento, possibilita que o bebê e os adultos passem a compartilhar estados afetivos subjetivos, o que caracteriza, pois, o desenvolvimento do self subjetivo desse bebê.

Assim, a partir do desenvolvimento do self subjetivo do bebê, ele desenvolve os comportamentos de atenção compartilhada, que, segundo Tomasello (2003), é definida pelos comportamentos comunicativos não verbais utilizados pelo bebê para seguir, compartilhar ou direcionar a atenção do adulto para algum evento ou objeto que seja de seu interesse. É a partir dos comportamentos de atenção compartilhada que as crianças demonstram comportamentos verdadeiramente intencionais, visto que, através dos gestos, elas procuram atingir determinados fins.

Para Hobson (2005c), o fomento da atenção compartilhada só é possível quando o bebê está tão conectado afetivamente aos seus cuidadores que passa a ser capaz de compartilhar com eles estados afetivos e de atenção. Isso o capacitará ao desenvolvimento da referenciação social, já no primeiro ano de vida. Assim, através da atenção compartilhada, a criança passa a saber que toda expressão de afeto de seus parceiros de interação tem um significado na situação compartilhada, o que afeta o significado que tal situação tem para ela (Hobson, 2002). Nesse caso, a criança desenvolve a referenciação social, que caracteriza a capacidade de a criança mudar a sua resposta afetiva sobre uma situação devido à expressão de afeto que o cuidador nela manifesta.

Do mesmo modo, a partir do momento em que as crianças percebem que as pessoas apresentam focos de atenção distintos e orientações subjetivas próprias para um mundo compartilhado, elas passam a ser capazes de identificar os estados mentais das pessoas, desenvolvendo, pois, a teoria da mente (Hobson, 2002). Essa percepção as capacita a reconhecer que as pessoas podem atribuir diversos significados aos eventos e objetos do mundo sem se basear apenas em suas percepções imediatas, passando a representar o mundo de acordo com as suas próprias atribuições ou através das atribuições de seu contexto social. Somente dessa maneira, então, as crianças desenvolvem três importantes comportamentos. O primeiro é o jogo simbólico, definido por Leslie (1987) como a capacidade de o ser humano utilizar um objeto ou situação como se fosse outra coisa. O segundo é o desenvolvimento da fala, e o terceiro, a aquisição das regras sociais, isso porque os significados dados para os objetos do 
mundo, as palavras e as regras e as convenções sociais dependem também das atribuições compartilhadas por determinado grupo social (Hobson, 2005b). Sendo assim, apenas quando a criança se torna capaz de compartilhar o seu foco de atenção e estados afetivos subjetivos com o seu parceiro de interação através da atenção compartilhada ela se torna capaz de dar significado aos eventos e objetos do mundo e de compartilhar das normas e as convenções de seu meio social.

Além disso, tal habilidade permite também à criança desenvolver a sua autoconsciência, ou seja, a capacidade de refletir sobre as suas próprias ações e comportamentos (Hobson, Chidambi, Lee, \& Meyer, 2006). À medida que ela está engajada na resposta afetiva do outro nas situações compartilhadas, passa a usar essa resposta para controlar e planejar o seu próprio comportamento, passando, pois, a refletir sobre as suas próprias condutas. Nesse caso, a resposta afetiva advinda de um comportamento do outro faz com que a criança desenvolva a capacidade de utilizar essa resposta para conduzir as suas ações e comportamentos.

Em suma, a conexão afetiva é a capacidade que fundamenta o desenvolvimento infantil e capacita a vida social do ser humano. A partir desse entendimento, podemos, então, pensar sobre o que ocorre de modo distinto no desenvolvimento da criança autista.

Segundo o DSM-IV-TR (2002), o transtorno autista se insere nos transtornos globais do desenvolvimento e é definido por uma tríade de prejuízos que se iniciam até os três anos de vida das crianças. Essa tríade é constituída por prejuízos severos em três principais áreas: interações sociais, com a criança apresentando dificuldades intensas em iniciar e manter interações com as pessoas a sua volta, comunicação, com a criança apresentando déficits significativos na compreensão, expressão e produção de comportamentos comunicativos não verbais e verbais, e comportamento, com a criança apresentando interesses restritos e repetitivos, ausência de brincar convencional e comportamentos não usuais, como birras, choros e autoagressão.

Atualmente, uma outra característica tem sido enfatizada também para a compreensão e a identificação do transtorno, que são as alterações sensoriais dos autistas, como eles apresentam hipo ou hipersensibilidade a determinados estímulos ou diminuição do limiar de dor (Baranek, David, Poe, Stone, \& Watson, 2006).

Deacordocomaabordagem desenvolvimentista, com as falhas iniciais na capacidade inata de conexão afetiva, os autistas apresentam prejuízos severos em sua capacidade de se envolver nas relações com o seu mundo social (Hobson et al., 2006). Isso ocasiona prejuízos nas relações denominadas pelos autores de I-Thou (Eu-Tu), ao passo que os autistas são capazes de estabelecer relações com o mundo não social, relações essas denominadas pelos autores de I-It (Eu-Isto). Em consequência, isso faz com que o desenvolvimento da criança autista sofra um desvio se comparado à trajetória seguida pelo desenvolvimento da criança típica, tanto no desenvolvimento da intersubjetividade primária quanto no da intersubjetividade secundária. No primeiro caso, a criança com risco autístico não conseguiria desenvolver o seu self emergente e nuclear, o contato ocular, as interações contingentes e de alternância de turno e o comportamento antecipatório, o sorriso responsivo e as vocalizações. Se tal fato se verificar, provavelmente as suas interações triádicas não podem desenvolverse adequadamente, gerando, pois, um desvio ainda mais severo para o seu desenvolvimento. Vejamos as evidências.

Com as falhas na capacidade inata de conexão afetiva, as primeiras experiências fisiológicas e sensoriais da criança com risco autístico não são associadas às suas experiências afetivas, o que equivale a dizer que, nesse 
caso, não há a correspondência dual entre as sensações e os afetos (Greenspan \& Benderly, 1999). Ao mesmo tempo, se consideramos as desordens sensoriais encontradas nos autistas (Baraneck et al., 2006), é provável realmente que o self emergente do bebê apresente um desenvolvimento peculiar em relação ao desenvolvimento da criança típica. Sendo assim, podemos inferir que as experiências sensoriais e afetivas do bebê com risco de autismo não acarretam uma experiência integradora para esse bebê, o que, provavelmente, contribuirá para todo o desvio do desenvolvimento dessa criança.

Várias pesquisas sobre a identificação precoce dos primeiros sinais do transtorno indicam que tais inferências parecem comprovar-se (Adrien et al., 1993; Braido, 2006; Lampreia \& Lima, 2008; Maestro et al., 2001; Osterling \& Dawson, 1994). Considerando as interações diádicas, vemos como o bebê com risco de autismo pode apresentar dificuldades em ser sensível ao afeto do outro a ponto de não conseguir responder e manter uma tentativa de contato de seu cuidador (Trevarthen \& Daniel, 2006) e não apresentar ajustamento corporal ao colo da mãe (Adrien et al., 1993), característica enfatizada por Kanner (1943) como um dos indícios de que o autista nasce com falhas na capacidadede estabelecer contato afetivo com as pessoas. Os vídeos caseiros de crianças autistas, filmadas antes dos dois primeiros anos de vida, também mostram os prejuízos dessas crianças na atenção às pessoas, ausência de resposta afetiva ao contato social do outro, falhas em procurar os parceiros de interação para expressar o seu prazer e alegria e ausência de movimentos antecipatórios (Adrien et al., 1993; Maestro et al., 2001; Osterling \& Dawson, 1994).

Klinger e Dawson consideram que a maior dificuldade da criança autista se encontra em sua capacidade de vivenciar a reciprocidade contida nas interações, quando não apresenta a capacidade de agir e de aguardar a reação de seu companheiro de interação. Para as autoras, tal dificuldade prejudica severamente o estabelecimento das interações sociais e acarreta também o prejuízo no aparecimento de muitos comportamentos, como o contato ocular, o sorriso responsivo e as vocalizações utilizadas para a comunicação, prejuízos identificados também pelas pesquisas que utilizam os vídeos caseiros (Adrien et al., 1993; Maestro et al., 2001; Osterling \& Dawson, 2004). Tudo isso indica que os prejuízos das crianças autistas já aparecem nas primeiras interações diádicas, o que afeta o aparecimento de seu self emergente e, em consequência, o de seu self nuclear. Tal deficiência faz com que a criança autista provavelmente apresente prejuízos significativos em vivenciar experiências integradoras de seu corpo físico.

Nesse caso, continuando a linha de raciocínio, se a criança autista apresenta prejuízos no desenvolvimento de seu self emergente e nuclear, o seu self subjetivo também não se desenvolve adequadamente. Desse modo, a criança autista apresenta limitações severas em sua capacidade de compartilhar estados afetivos subjetivos com os seus parceiros de interações, e, com isso, não é capaz de compartilhar o seu foco de atenção com as pessoas e vice-versa (Hobson, 2005c). Assim, a criança autista apresenta déficits severos em sua capacidade de envolver-se em interações triádicas com os seus parceiros de interações, o que é identificado através dos principais prejuízos encontrados no seu desenvolvimento pela literatura sobre o transtorno: prejuízos na atenção compartilhada, na capacidade de referenciação social, na teoria da mente, nos jogos simbólicos, na fala, na aquisição de regras sociais e na autoconsciência (Carpenter, Nagell, \& Tomasello, 1998; Carpenter \& Tomasello, 2000; Hobson, 1993, 2002, 2005b, 2005c; Hobson et al., 2006; Hobson, Lee, \& Hobson, 2009; Tomasello, 2003).

Em relação aos prejuízos na atenção compartilhada, Hobson (2005c) enfatiza que a 
criança autista, por apresentar graves limitações em sua capacidade de compartilhar os seus estados afetivos subjetivos, apresenta prejuízos severos na capacidade de identificar o foco de atenção das pessoas e de perceber que esse foco pode ser compartilhado. Sendo assim, ela apresenta prejuízos severos na capacidade de identificar e de compartilhar a atenção, as intenções e os estados mentais tanto dela quanto das outras pessoas (Hobson, 2005c). Tudo isso ocasiona também os déficits na capacidade de referenciação social e no aparecimento da teoria da mente e do jogo simbólico. Em relação ao primeiro, a criança autista não utiliza a resposta afetiva das pessoas para expressar o seu próprio comportamento, e é por esse motivo que elas se assustam com alguns objetos, por exemplo, e mexem em outros que nos causam pavor (Hobson, 2002). Em relação à teoria da mente e ao jogo simbólico, como as crianças deixam de interagir com as pessoas que apresentam focos de atenção e orientações subjetivas próprias, elas não compreendem que as pessoas apresentam estados mentais próprios e dão diversos significados para os eventos do mundo, não compartilhando também os diversos significados de seu mundo social (Hobson, 2002).

Junto a eles, os autistas apresentam, então, déficits significativos em sua capacidade de usarem os significados convencionais das palavras de seu grupo social, como no uso da fala espontânea e prejuízos na capacidade de compreender e de adquirir regras e convenções sociais (Hobson, 2005b). Além disso, tais prejuízos culminam com os prejuízos na capacidade de autoconsciência, na medida em que a criança autista não se baseia na resposta afetiva do outro para refletir acerca de seus próprios comportamentos e ações (Hobson et al., 2006).

Essas evidências revelam o fato de que os prejuízos afetivos da criança autista se encontram já em suas primeiras interações e são os mesmos que geram todo o desvio no seu desenvolvimento. Contudo, apesar da ênfase na detecção precoce dos primeiros sinais do transtorno para se atuar rapidamente sobre eles, as intervenções precoces não parecem considerar adequadamente esses prejuízos iniciais ao planejar as suas estratégias de tratamento, e, quando o fazem, apresentam limitações quanto à objetividade nas estratégias do programa. É o que será visto a seguir.

\section{As intervenções precoces de base desenvolvimentista}

Os programas que utilizam a abordagem desenvolvimentista afirmam que é fundamental para a diminuição do desvio do desenvolvimento da criança autista o desenvolvimento da sua comunicação inicial e da intenção comunicativa, habilidades que a capacitam a interagir, a comunicar-se e a desenvolver comportamentos próprios do desenvolvimento infantil típico (Greenspan \& Wieder, 2006; Klinger \& Dawson, 1992; Prizant et al., 2003). Essa comunicação inicial abrange todos os comportamentos comunicativos da criança, sejam eles verbais ou não verbais. Afinal, para essa abordagem, o importante é ajudar essa criança a comunicarse e a interagir adequadamente com os seus parceiros de interações, o que é feito baseandose na criação de estratégias que impelem a criança a comunicar-se naturalmente através de uma necessidade ou interesse. Devido a isso, essa abordagem utiliza contextos naturais de interações para que as crianças desenvolvam espontaneamente os seus comportamentos comunicativos.

Como os contextos naturais de interações são imprescindíveis para que a criança se comunique e interaja naturalmente, essa abordagem utiliza a família como um dos principais fomentos do desenvolvimento de sua criança. Ela é considerada o apoio fundamental para que a criança interaja e se comunique através dos mais variados contextos 
de interações, sejam eles a hora do banho, a de brincar ou até mesmo a hora das refeições. O importante, conforme já dito, é que a criança desenvolva os seus comportamentos de modo espontâneo, flexível e natural (Prizant, Wetherby, \& Rydell, 2000).

Apesar de existirem alguns programas de intervenção precoce de base desenvolvimentista (Greenspan \& Wieder, 2006; Klinger \& Dawson, 1992; Prizant et al., 2003. Schuler \& Wolfberg, 2000) nós nos ateremos a dois principais programas conhecidos mundialmente.

O primeiro é chamado de SCERTS (Prizant et al, 2003), e pode ser aplicado a partir dos dezoito meses de idade da criança, quando geralmente ocorre a identificação inicial dos primeiros sinais do transtorno. As iniciais SCERTS referem-se aos três objetivos almejados pelo programa. O primeiro deles é o desenvolvimento da comunicação social dessas crianças, por isso o SC do nome, que significa social communication. Nesse objetivo, as crianças autistas devem desenvolver a capacidade de atenção compartilhada, a reciprocidade social e o uso do símbolo.

O segundo objetivo é o da regulação emocional, daí a sigla ER do programa, que significa emotional regulation. Isso equivale a dizer que a criança autista deve ser capaz de regular os seus próprios afetos e seu estado de alerta, seja de forma independente, seja através da regulação mútua com os seus parceiros de interações.

O último objetivo é o suporte transacional, o TS da sigla do programa, que significa transactional support. Em tal objetivo, o importante é oferecer, em todos os ambientes que a criança circula, oportunidades ideais para que ela desenvolva habilidades e amenize as suas dificuldades o que constitui um suporte à família e aos profissionais envolvidos na escola.

Em síntese, o SCERTS focaliza, através de um planejamento altamente individualizado que inclui a avaliação do nível do desenvolvimento da criança e dos diversos contextos que podem ajudá-la a desenvolver-se, o fomento global da criança autista. Para tal, há a ênfase no desenvolvimento dos comportamentos comunicativos da atenção compartilhada, o uso dos sistemas simbólicos, a identificação das alterações sensoriais da criança que podem prejudicar o foco de sua atenção para as interações e o suporte adequado à família e a todas as pessoas envolvidas no cuidado da criança, de modo a capacitá-las a estimular essa criança a interagir e a se comunicar.

O segundo programa é denominado DIR (Developmental individual-difference, relationship based model intervention program), e caracteriza um programa de intervenção que se baseia no relacionamento e na diferença individual de cada criança atendida. Ele também costuma ser aplicado assim que os primeiros sinais do transtorno são identificados, geralmente, aos dezoito meses de vida da criança. Desenvolvido por Greenspan e Wieder, o DIR tem como objetivo retomar o desenvolvimento saudável da criança autista através do fomento das interações afetivas que a capacitam a engajá-la em comunicações significativas, participação social, desenvolvimento simbólico e cognitivo.

Como o programa se fundamenta no relacionamento afetivo da criança autista, utiliza como principal estratégia o floortime (tempo no chão), em que a criança autista e os seus cuidadores passam um tempo brincando e interagindo livremente. Desse modo, Greenspan e Wieder $(2000,2006)$ acreditam que a criança possa envolver-se em interações afetivas com os seus cuidadores e assim desenvolver as áreas necessárias para o seu fomento.

Essas áreas dependem de a criança autista percorrer seis estágios do desenvolvimento infantil. O primeiro estágio é o da regulação e interesse no mundo, no qual a criança busca informações sobre o mundo através de suas experiências afetivas com os seus parceiros 
de interações; o segundo é o engajamento e o relacionamento da criança, em que a criança autista busca os padrões afetivos nos comportamentos de seus parceiros de interações para interagir mais adequadamente; o terceiro é o do desenvolvimento da intencionalidade e da comunicação de duas vias, o que equivale a dizer que a criança autista precisa comunicar-se com as pessoas através de sinais afetivos e de comportamentos que não sejam estritamente verbais; o quarto estágio envolve o fomento de solução de problema social, regulação de humor e formação de um sentido de self. Nesse estágio, a criança autista deve ser capaz de utilizar os seus sinais afetivos e comportamentos comunicativos não verbais para solucionar problemas, regular os seus afetos através deles, além de vivenciar um sentido de autodefinição ao reconhecer a sua identidade na agência dessas ações. Já o quinto estágio é o da criação de símbolos e o uso de palavras e ideias. Por fim, no estágio seis, que é o do pensamento emocional, lógico e senso de realidade, a criança autista precisa envolver-se em interações afetivas que a façam conectar ideias e padrões.

Em síntese, o DIR sustenta que, para que todos estes estágios sejam desenvolvidos, a criança autista precisa envolver-se em interações afetivas com os seus cuidadores. Afinal, todas as áreas do desenvolvimento infantil estão inter-relacionadas. Dessa forma, a partir das interações com as pessoas, a criança autista pode comunicar-se, solucionar problemas, desenvolver o seu self, compartilhar significados sociais, palavras e conectar ideias, ou seja, todas as áreas necessárias para o seu desenvolvimento global.

Tanto o SCERTS quanto o DIR fundamentam o seu programa no fomento individual de cada criança autista. Em ambos os programas, a avaliação consiste em identificar onde a criança autista se encontra em relação a cada objetivo (SCERTS) e aos níveis de desenvolvimento (DIR), de modo_a saber o que ela ainda precisa desenvolver.

Como a singularidade é enfatizada em ambos os programas, as interações entre cada criança e os seus parceiros são vitais para as estratégias de cada programa. Mas os programas enfatizam ganhos diferentes com elas. A grande ênfase do SCERTS é no desenvolvimento da atenção compartilhada, a autorregulação da criança autista e a sua capacidade para interagir e comunicar-se em diversos contextos. A do DIR é o relacionamento afetivo da criança com os seus parceiros de interação. Encontramos tal ênfase no programa SCERTS, no entanto, ela não é considerada estratégia fundamental, mas apenas uma das conquistas a ser conseguida pelas crianças autistas. Por outro lado, o DIR, ainda que almeje que a criança autista se relacione afetivamente com as pessoas ao seu redor, interagindo e comunicandose nas situações cotidianas e naturais da criança, e aborde as questões sensoriais da criança como algo a ser cuidado para que ela se engaje afetivamente às pessoas, não enfatiza o desenvolvimento da atenção compartilhada. E, como visto anteriormente, tal habilidade é um precursor fundamental para o desenvolvimento simbólico, a fala, a aquisição de regras sociais e a autoconsciência, ou seja, as habilidades fundamentais para que a criança autista realmente compartilhe dos significados atribuídos por seu grupo social.

Mas, por outro lado, o SCERTS não enfatiza a capacidade primordial do desenvolvimento humano, que é a capacidade humana de interação com o outro através das experiências afetivas entre as pessoas. Com isso, o programa deixa de levar em consideração que a conexão afetiva é o precursor do desenvolvimento humano e, em consequência, da atenção compartilhada. Afinal de contas, se o bebê humano não é capaz de ser expressivo, sensível e responsivo ao afeto do outro, ele não poderá compartilhar afetos subjetivos com ele. E o DIR procura considerar o afeto entre as pessoas 
a base para o ganho simbólico, linguístico e cognitivo do bebê humano. O que ele apenas deixa de fazer é ser mais objetivo em como podemos ajudar essas crianças a se conectarem afetivamente a essas pessoas, não apresentando aos interessados uma metodologia para o seu atendimento.

García-Perez, Lee e Hobson (2007) criaram uma metodologia para identificarmos, a partir de critérios objetivos, a conexão afetiva das pessoas. Um deles é a sensação que sentimos quando estamos conectados às pessoas, sensação essa que identifica quando as pessoas estão sendo responsivas aos nossos afetos. $\mathrm{O}$ outro se relaciona ao fluxo de interações que conseguimos manter com as pessoas. Se esse fluxo for harmônico, sem necessidade de esforço para que a interação ocorra, possivelmente estamos conectados afetivamente aos nossos parceiros de interação. E, por fim, um outro critério objetivo se relaciona ao uso de mais de um comportamento não verbal utilizado pela criança em uma interação, o que demonstra o seu envolvimento afetivo pelo parceiro.

Considerando o exposto, embora os autores não afirmem como fazer para que a conexão afetiva ocorra nas interações com as crianças autistas, eles já nos oferecem ferramentas para que possamos identificar a conexão afetiva das pessoas, o que pode ser o caminho para que possamos intervir nessa conexão. Esse foi o trabalho de Fiore-Correia (2010), que procurou, baseada na metodologia utilizada pelos autores, desenvolver a conexão afetiva de crianças autistas recém-diagnosticadas. Seguindo o pensamento de Wimpory, Hobson e Nash (2007), certas interações sociais iniciadas pelos adultos, como as que utilizam atividades motoras e musicais para chamar a atenção das crianças e as que utilizam os seus interesses para que tenham necessidade de se comunicar e que se baseiam na rotina das crianças e na imitação de seus comportamentos, possibilitam o envolvimento das crianças autistas em episódios de engajamento social. Baseada nisso, a autora procurou, em cada caso, estruturar situações singulares de acordo com o interesse de cada criança que as levassem a prestar atenção às pessoas e, posteriomente, a apresentar tipos de interações sociais descritas na literatura desenvolvimentista. Fazendo isso, elas puderam conectar-se ao afeto da pesquisadora e envolverse mais adequadamente nas interações sociais.

Considerando tal enfoque, é possível tentar desenvolver a conexão afetiva nas crianças autistas, e o DIR nos mostra que isso é viável, embora não diga especificamente como. Esse trabalho fica a cargo do SCERTS, porém apenas a partir do desenvolvimento da comunicação advinda da atenção compartilhada e adiante, o que nos leva a concluir que o que o programa DIR faz é enfatizar que é o prejuízo primário na capacidade de conexão afetiva das crianças autistas que prejudica o percurso dos seis níveis de desenvolvimento típico. Ao desenvolvêla, a criança se torna capaz de percorrê-los. Contudo, o DIR não mostra como executar o percurso dos níveis, e não enfatiza os comportamentos da atenção compartilhada em seus níveis de desenvolvimento. Em nossa opinião, portanto, o programa não acompanha adequadamente o desenvolvimento da criança típica para identificar o que ocorre de distinto no desenvolvimento da criança autista que necessita ser alvo de intervenção para que possa haver a diminuição no desvio do seu desenvolvimento.

Porém, o mesmo pode ser dito em relação ao programa SCERTS. Afinal, a linha do desenvolvimento infantil típico tem como fundamento a capacidade de conexão afetiva do recém-nascido. Não considerar isso, como o SCERTS, é não enfatizar os precursores de comportamentos que oferecem condições para o aparecimento da atenção compartilhada e de seus comportamentos subsequentes. E, ao não fazê-lo, o programa não consegue intervir nos prejuízos primários do transtorno, mas apenas naqueles que se sucedem a estes. Essa nos parece ser a maior falha do programa SCERTS. 
Afinal, conforme vimos, são esses prejuízos primários na capacidade de conexão afetiva que ocasionam o desvio do desenvolvimento da criança autista; portanto, são eles que precisam ser enfatizados se o atendimento às crianças autistas visa a amenizar ou até a impedir esse desvio.

Encerrando, portanto, podemos concluir que os principais programas de intervenção precoce de base desenvolvimentista pecam ao não usar adequadamente o desenvolvimento infantil típico como parâmetro para o entendimento das dificuldades da criança autista, parâmetro esse que nos indica o que é preciso fazer para que as crianças autistas possam seguir essa linha de desenvolvimento, o que pode garantir-lhes a verdadeira inserção nos sistemas simbólico, linguístico, cultural e normativo de seu grupo social. Nesse caso, o DIR parte do prejuízo primário do transtorno autista, mas, além de não nos oferecer ferramentas para que sanemos esse prejuízo, não trata adequadamente todos os prejuízos secundários do transtorno. Já o SCERTS salienta os prejuízos secundários do transtorno autista, mas não considera que, apenas quando cuidamos dos primários podemos também intervir adequadamente nos secundários, fazendo, assim, com que a criança autista se desenvolva o mais tipicamente possível. O ideal talvez fosse que esses programas pudessem integrar os seus princípios e estratégias, de modo a garantir que as crianças autistas tivessem os seus prejuízos primários e secundários devidamente assistidos. Afinal, ambos os programas são fundamentais para o atendimento das crianças autistas e imprescindíveis para assegurar melhor prognóstico para todas elas. O importante é compreender que o desenvolvimento da conexão afetiva das crianças autistas precisa ser estratégia imprescindível dos programas de intervenção precoce de base desenvolvimentista. E, ao darmos a oportunidade para que essas crianças se conectem ao afeto do outro, damos condições para o aparecimento de interações sociais e de comportamentos fundamentais para o seu desenvolvimento.

\section{Considerações finais}

O presente trabalho teve como objetivo salientar a importância da conexão afetiva para o desenvolvimento das crianças autistas, e, como tal, enfatizar que essa capacidade deveria ser considerada a principal estratégia de intervenções precoces que utilizam a abordagem desenvolvimentista. Para alcançarmos esse objetivo, traçamos a linha do desenvolvimento infantil típico para identificarmos interações e comportamentos do desenvolvimento humano que são desenvolvidos a partir da capacidade de a criança se conectar ao afeto do outro, ou seja, ser capaz de ser expressiva, sensível e responsiva ao afeto das pessoas, o que lhe permite engajar-se em interações sociais, desenvolver comportamentos que intensificam ainda mais as interações afetivas com as pessoas, como o sorriso responsivo e as vocalizações, e construir o seu self. Somente assim a criança se torna apta a compartilhar estados afetivos subjetivos, conseguindo compartilhar também atenção, intenções e estados mentais, o que Ihe permite desenvolver comportamentos mais complexos do desenvolvimento humano, como a referenciação social, o jogo simbólico, a fala, a aquisição de regras sociais e a autoconsciência.

No caso da criança autista, compreendendo a linha do desenvolvimento infantil típico, pudemos identificar o que ocorre de diferente no seu desenvolvimento para podermos intervir a partir daí. Considerando isso, vimos que falhas inatas na capacidade de conexão afetiva das crianças autistas ocasionam prejuízos severos em suas interações sociais, desenvolvimento de comportamentos e aparecimento de self. Como resultado, a criança autista passa a ter prejuízos severos em sua capacidade de compartilhar estados afetivos subjetivos, não conseguindo compartilhar adequadamente atenção, intenção e estados mentais. Nesse caso, o seu comportamento deixa de se basear 
na resposta afetiva de seu parceiro de interação e nos significados que ele dá ao mundo, o que traz prejuízos ao seu desenvolvimento simbólico, fala e aquisição de regras sociais.

Dois importantes programas de intervenção precoce de base desenvolvimentista, o SCERTS e o DIR, procuram fazer, através do fomento das interações sociais e da comunicação inicial da criança autista, que ela diminua o desvio em seu desenvolvimento. No caso do DIR, ele procura envolver as crianças autistas em interações afetivas com os seus parceiros de interação, embora não nos diga como fazê-lo, além de não identificar, através dos estudos advindos da abordagem desenvolvimentista, como os trabalhos de Hobson (1990, 1993a, 1993b, 1998, 2002, 2005a, 2005b, 2005c, 2007, 2009), os prejuízos que se sucedem às falhas de conexão afetiva e que, obviamente, precisam também ser considerados para que se consiga diminuir o desvio no desenvolvimento da criança autista atendida.

Já o SCERTS focaliza a comunicação inicial da criança autista a partir da atenção compartilhada, sem considerar que o prejuízo primário na capacidade de conexão afetiva é o que acarreta os prejuízos na atenção compartilhada e todos os outros subsequentes. E isso é fundamental para que possamos ajudar a criança autista a desenvolver-se o mais tipicamente possível.

Devido ao que foi exposto, é importante fazer mais alguns apontamentos. O primeiro é que compreendamos que o conhecimento a respeito do desenvolvimento infantil típico é considerado pela abordagem desenvolvimentista como o orientador para o que é preciso desenvolver na criança autista, de modo a lhe garantir um melhor prognóstico. O segundo é que apenas ao fazermos isso conseguimos identificar a conexão afetiva, as interações sociais e os comportamentos que necessitam ser considerados individualmente nas estratégias de intervenção precoce às crianças autistas. Somente assim podemos tentar desenvolvê-los em cada criança atendida. Esses dois apontamentos parecem ter sido negligenciados pelos programas DIR e SCERTS e necessitam ser focalizados nas intervenções precoces com as crianças autistas ou com risco autístico.

Já o terceiro apontamento nos lembra que, se autores como García-Perez et al. (2007) identificam a conexão afetiva, dimensão subjetiva do desenvolvimento humano, a partir de critérios objetivos, precisamos criar estratégias também objetivas que consigam desenvolvê-la. Esse é o desafio do DIR e a nossa principal crítica. Mas, conforme já dissemos anteriormente, os trabalhos de García-Perez et al. (2007) e Wimpory et al. (2007) lançam luz nessa empreitada, que parece ser possível, conforme o trabalho de Fiore-Correia (2010), também citado.

Mas, em todo o caso, considerando os programas apresentados, diferentemente do SCERTS, o DIR retornou à origem do desenvolvimento humano para enfatizar que a conexão afetiva é a base para o nosso desenvolvimento simbólico, linguístico e cognitivo. O que falta é apenas mais objetividade, além de considerar alguns comportamentos que são fundamentais também para o nosso desenvolvimento, como a atenção compartilhada. Nesse ponto, o SCERTS pode ser uma boa influência para o programa DIR, desde que este também mostre ao primeiro o papel da conexão afetiva para o desenvolvimento da criança autista. Desse modo, ambos os programas, assim como todos os outros que utilizam a abordagem desenvolvimentista, e ainda os outros que são influenciados por outras abordagens teóricas, devem considerar que a conexão afetiva é o principal prejuízo do transtorno autista e a principal responsável pelo desvio do desenvolvimento da criança autista. Logo, criar estratégias para desenvolvermos a conexão afetiva nessas crianças pode ser o que precisávamos para ajudá-las a percorrer outro caminho em seu desenvolvimento. 


\section{Olívia Fiore-Correia}

Psicóloga, Especialista em Saúde Mental da Infância e Adolescência pelo IPUB/UFRJ, Mestre e Doutora em Psicologia Clínica pela PUC-Rio, Rio de Janeiro - RJ - Brasil.

E-mail: lifiore07@gmail.com

\section{Carolina Lampreia}

Doutora em Psicologia Clínica pela Pontifícia Universidade Católica do Rio de Janeiro, professora do Programa de Pós-Graduação em Psicologia Clínica do Departamento de Psicologia da PUC-Rio, Rio de Janeiro - RJ - Brasil. E-mail: lampreia@puc-rio.br

\section{Endereço para envio de correspondência:}

Pontifícia Universidade Católica do Rio de Janeiro, Departamento de Psicologia. Rua Marques de São Vicente, 225, sala 201L, Gávea. CEP: 22453-900;

Recebido 23/06/2011, 1a Reformulação 24/08/2012, Aprovado 15/10/2012.

\section{Referências}

Adrien, J., Lenoir, P., Martineau, J., Perrot, A. Hameury, L., Larmande, C. et al. (1993). Blind ratings of early symptoms of autism based upon family home movies. Journal of the American Academy of Child and Adolescent Psychiatry, 32(3), 617-626.

American Psychiatric Association. (2002). DSM-IV-TR: Manual Diagnóstico e Estatístico de Transtornos Mentais (4a ed. rev., C. Dornelles, trad.). Porto Alegre: Artes Médicas (Trabalho original publicado em 2000).

Baranek, G. T., David, F. J., Poe, M. D., Stone, W. L., \& Watson, L. R. (2006). Sensory experiences questionnaire: Discriminating sensory features in young children with autism, developmental delays and typical development. Journal of Child Psychology and Psychiatric, 46(1), 1-11.

Bates, E. (1979). The emergence of symbols. Cognition and communication in infancy. N.Y.: Academic Press.

Braido, M. L. G. (2006). Identificação precoce dos transtornos do espectro autista: um estudo de vídeos familiares. Dissertação de mestrado. Departamento de Psicologia, Pontifícia Universidade Católica do Rio de Janeiro, RJ.

Brazelton, T., \& Cramer, B. (1990). The earliest relationship: Parents, infants and the drama of early attachment: A Merloyd Lawrence Book.
Caminha, R. C. (2008). Autismo: um transtorno da natureza sensorial? Dissertação de mestrado. Departamento de Psicologia, Pontifícia Universidade Católica do Rio de Janeiro, RJ.

Campos, A. M. C. (2007). Observando a conexão afetiva em crianças autistas. Dissertação de mestrado. Departamento de Psicologia, Pontifícia Universidade Católica do Rio de Janeiro, RJ.

Carpenter, M., Nagell, K., \& Tomasello, M. (1998). Social cognition, joint attention and communicative competence from 9 to 15 months of age. Chicago: The University of Chicago Press.

Carpenter, M., \& Tomasello, M. (2000). Joint attention, cultural learning and language acquisition: Implications for children with autism. In A. Wetherby \& B. Prizant (Eds.). Autism spectrum disorders - A transactional developmental perspective (pp. 31-54). Baltimore: Paul H. Brookes.

Fiore-Correia, O. B. (2005). A aplicabilidade de um programa de intervenção precoce em crianças com possível risco autístico. Dissertação de mestrado. Departamento de Psicologia, Pontifícia Universidade Católica do Rio de Janeiro, RJ.

Fiore-Correia, O. B. (2010). O papel da conexão afetiva na construção de um programa de intervenção precoce para crianças recém-diagnosticadas autistas ou com risco autístico. 
Tese de doutorado. Departamento de Psicologia, Pontifícia Universidade Católica do Rio de Janeiro, RJ.

Fiore-Correia, O. B., Lampreia, C., \& Sollero-de-Campos, F. (2008). As falhas na emergência da autoconsciência na criança autista. Psicologia Clínica, 22(1), 99-121.

García-Perez, R., Lee, A., \& Hobson, P. (2007). On intersubjective engagement in autism: A controlled study of nonverbal aspects of conversation. Journal of Autism and Developmental Disorders, 37(7), 1310-1322.

Greenspan, S., \& Benderley, B. (1999). A evolução da mente - As origens da inteligência e as novas ameaças a seu desenvolvimento (M. Monte, trad.). Rio de Janeiro: Record.

Greenspan, S., \& Wieder, S. (2000). A developmental approach to difficulties in relating and communicating in autism spectrum disorders and related syndromes. In A. Wetherby \& B. Prizant (Orgs.). Autism spectrum disorders. A transactional developmental perspective (pp. 279-231). Baltimore: Paul H. Brookes.

Greenspan, S., \& Wieder, S. (2006). Engaging autism - using the floortime approach to help children relate, communicate and think. Cambridge: Da Capo Lifelong Books.

Hobson, P. (1990). On acquiring knowledge about people and the capacity to pretend: Response to Leslie (1987). Psychological Review, 97(1), 114-121.

Hobson, P. (1993a). Autism and development of mind. Hove, Sussex: Erlbaum.

Hobson, P. (1993b). The emotional origins of social understanding. Philosophical Psychology, 6(3), 1-27.

Hobson, P. (1998). The intersubjective foundations of thought. In S. Bråten (Ed.) Intersubjective communication and emotion in early ontogeny (pp. 283-296). Cambridge: Cambridge University Press.

Hobson, P. (2002). The cradle of thought. London: MacMillan.

Hobson, P. (2005a). Autism and emotion. In F. R. Volkmar, R. Paul, A. Klin \& D. Cohen (Eds.). Handbook of autism and pervarsive developmental disorders (Vol 1, 3rd. ed., pp. 406422). New York: Wiley.

Hobson, P. (2005b). Social engagement and understanding in chimpanzees and humans. Monographs of the Society for Research in Child Development, 70(1), 133-152.

Hobson, P. (2005c). What puts the jointness into joint attention? In N. Eilan, C. Hoerl, T. McComarck \& J. Roessler (Eds.). Joint attention: Communication and other minds (pp. 185-204). Oxford: Wiley.

Hobson, P. (2007). Communicative depth: Soundings from developmental psychopathology. Infant Behavior \& Development, 30, 267-277.

Hobson, P. (2009). Wittgenstein and the developmental psychopathology of autism. New Ideas in Psychology, 27, 243-257.

Hobson, P., Chidambi, G., Lee, A., \& Meyer, J. (2006). Foundations for self-awareness: An exploration through autism. Monographs of the Society for Research in Child Development, 71(2), 1-188.

Hobson, P., Lee, A., \& Hobson, M. (2009). Qualities of symbolic play among children with autism. Journal of Autism and Developmental Disorders, 39, 12-22.

Kanner, L. (1943). Autistic disturbances of affective contact. Nervous Child, 2, 217-250.

Klinger, L., \& Dawson, G. (1992). Faciliting early social and communicative developmental in children with autism. In S. Warren \& J. Reichle (Eds.). Causes and effects in communication and language intervention (pp. 157-186). Baltimore: Paul H. Brookes.
Lampreia, C. (2004). Os enfoques cognitivista e desenvolvimentista no autismo: uma análise preliminar. Psicologia Reflexão e Crítica, 17(1), 111-120.

Lampreia, C. (2007). A perspectiva desenvolvimentista para a intervenção precoce no autismo. Estudos de Psicologia, 24(1), 105-114.

Lampreia, C., \& Lima, M. M. R. (2008). Instrumento de vigilância precoce do autismo: manual e vídeo. Rio de Janeiro: Ed. PUCRio; São Paulo: Loyola.

Leslie, A. (1987). Pretense and representation: The origin of "theory of mind". Psychological Review, 94(4), 412-426.

Maestro, S., Muratori, F., Barbieri, F., Casella, C., Cattaneo, V., Cavallaro, C., et al. (2001). The early behavioral development in autistic children: The first two years of life through the home movies. Psychopathology, 34(3), 147-152.

Oliveira, S. M. (2009). A clínica do autismo sob uma perspectiva desenvolvimentista: o papel doengajamento afetivo no desenvolvimento da comunicação e da linguagem. Dissertação demestrado. Departamento de Psicologia, Pontifícia Universidade Católica do Rio de Janeiro, RJ.

Osterling, J., \& Dawson, G. (1994). Early recognition of children with autism: A study of first birthday home videotapes. Journal of Autism and Developmental Disorders, 24(3), 247-257.

Prizant, B., Wetherby, A., Rubin, E., \& Laurent, A. (2003). The SCERTS model: A transactional, family-centered approach to enhancing communication and socioemotional abilities of children with autism spectrum disorder. Infants and Young Children, 16(4), 296-316.

Prizant, B., Wetherby, A., \& Rydell, P. (2000). Communication intervention issues for young children with autism spectrum disorders. In A. Wetherby \& B. Prizant (Eds.). Autism spectrum disorders. A transactional developmental perspective (pp. 193234). Baltimore: Paul H. Brookes.

Schuler, A., \& Wolfberg, P. (2000). Promoting peer play and socialization: The art of scaffolding. In A. Wetherby \& B. Prizant (Eds.). Autism spectrum disorders. A transactional developmenilliamtal perspective (pp. 251-277). Baltimore: Paul H. Brookes.

Stern, D. (1974). Mother and infant at play: The dyadic interaction involving facial, vocal and gaze behaviors. In M. Lewis \& $\mathrm{L}$. Rosenblum (Eds.). The effect of the infant on its caregiver (pp. 187-213). New York: John Wiley \& Sons.

Stern, D. (1992). O mundo interpessoal do bebê - uma visão a partir da psicanálise e da psicologia do desenvolvimento (M. A. V. Veronese, trad.). Porto Alegre: Artes Médicas.

Tomasello, M. (2003). Origens culturais da aquisição do conhecimento humano (C. Berliner, trad.). São Paulo: Martins Fontes.

Trevarthen, C., \& Aitken, K. (2001). Infant intersubjectivity: Research, theory and clinical applications. Journal of Child Psychology and Psychiatric, 42(1), 3-48.

Trevarthen, C., \& Daniel, S. (2005). Disorganized rhythm and synchrony; early signs of autism and Rett syndrome. Brain \& Development, 27, S25-S34.

Wimpory, D., Hobson, P., \& Nash, S. (2007). What facilitates social engagement in preschool children with autism? Journal of Autism and Developmental Disorders, 37(3), 564-573. 